\title{
Recent Advances in High Temperature Electrolysis at Idaho National Laboratory: Stack Tests
}

\section{ESFuelCell2012}

Xiaoyu Zhang

James E. O'Brien

Robert C. O'Brien

Joseph J. Hartvigsen

Greg Tao

Nathalie Petigny

U.S. Department of Energy

National Laboratory

operated by

Battelle Energy Alliance

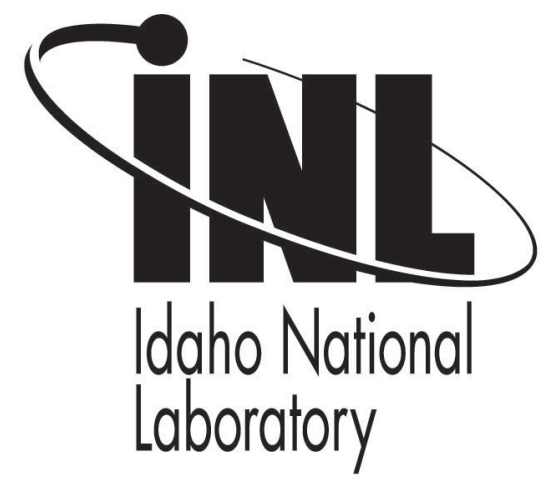

This is a preprint of a paper intended for publication in a journal or proceedings. Since changes may be made before publication, this preprint should not be cited or reproduced without permission of the author. This document was prepared as an account of work sponsored by an agency of the United States Government. Neither the United States Government nor any agency thereof, or any of their employees, makes any warranty, expressed or implied, or assumes any legal liability or responsibility for any third party's use, or the results of such use, of any information, apparatus, product or process disclosed in this report, or represents that its use by such third party would not infringe privately owned rights. The views expressed in this paper are not necessarily those of the United States Government or the sponsoring agency. 


\section{Proceedings of the ASME 2012 6th International Conference on Energy Sustainability \& 10th Fuel Cell Science, Engineering and Technology Conference \\ July 23-26, 2012, San Diego, CA, USA}

\section{ESFuelCell2012-91049}

\section{RECENT ADVANCES IN HIGH TEMPERATURE ELECTROLYSIS AT IDAHO NATIONAL LABORATORY: STACK TESTS}

\author{
Xiaoyu Zhang \\ Idaho National Laboratory \\ Idaho Falls, ID, United States \\ Joseph J. Hartvigsen \\ Ceramatec, Inc. \\ Salt Lake City, UT, United States
}

\author{
James E. O'Brien \\ Idaho National Laboratory \\ Idaho Falls, ID, United States \\ Greg Tao \\ Materials and Systems \\ Research, Inc. \\ Salt Lake City, UT, United States
}

\author{
Robert C. O'Brien \\ Center for Space Nuclear \\ Research \\ Idaho Falls, ID, United States \\ Nathalie Petigny \\ Saint-Gobain CREE \\ Cavaillon, France
}

\begin{abstract}
High temperature steam electrolysis is a promising technology for efficiently sustainable large-scale hydrogen production. Solid oxide electrolysis cells (SOECs) are able to utilize high temperature heat and electric power from advanced high-temperature nuclear reactors or renewable sources to generate carbon-free hydrogen at large scale. However, long term durability of SOECs needs to be improved significantly before commercialization of this technology. A degradation rate of $1 \% / \mathrm{khr}$ or lower is proposed as a threshold value for commercialization of this technology. Solid oxide electrolysis stack tests have been conducted at Idaho National Laboratory to demonstrate recent improvements in long-term durability of SOECs. Electrolytesupported and electrode-supported SOEC stacks were provided by Ceramatec Inc., Materials and Systems Research Inc. (MSRI), and Saint Gobain Advanced Materials (St. Gobain), respectively for these tests. Long-term durability tests were generally operated for a duration of 1000 hours or more. Stack tests based on technologies developed at Ceramatec and MSRI have shown significant improvement in durability in the electrolysis mode. Long-term degradation rates of 3.2\%/khr and 4.6\%/khr were observed for MSRI and Ceramatec stacks, respectively. One recent Ceramatec stack even showed negative degradation (performance improvement) over 1900 hours of operation. A three-cell short stack provided by St. Gobain, however, showed rapid degradation in the electrolysis mode. Optimizations of electrode materials, interconnect coatings, and electrolyte-
\end{abstract}

electrode interface microstructures contribute to better durability of SOEC stacks.

\section{INTRODUCTION}

Large-scale carbon-free hydrogen production based on high-temperature electrolysis is under investigation at Idaho National Laboratory (INL) as an alternative to steam methane reforming, which accounts for about $95 \%$ of current hydrogen production in the United States [1]. Most hydrogen consumption in North America is for petroleum refining, ammonia-based fertilizer production, and chemical industries [2]. Demand for hydrogen is increasing rapidly, primarily due to refining requirements for increasingly low quality petroleum resources such as oil sands and heavy crudes. Domestic hydrogen demand in 2040 is projected to increase up to 64 million metric tons [3], compared to 9 million metric tons in 2003 [2]. As the demand for hydrogen keeps increasing, the U.S. cannot rely solely on natural gas for hydrogen production. The greatest energy security vulnerability for the US is in the area of transportation fuels. Domestic hydrogen production based on nuclear or renewable energy allows these carbon-free energy resources to contribute to the transportation sector through petroleum refining, synthetic fuels production, or ultimately as a direct vehicle fuel.

From a long-term perspective, sustainable methods must be developed for large-scale hydrogen production [4]. A broad overview of hydrogen production technologies is presented in [5]. Among all the sustainable hydrogen production methods, 
high temperature electrolysis (HTE) is one of the most promising technologies that can be used for large-scale hydrogen production [6]. Based on the recommendation of an independent review team [7], HTE was selected by the US DOE as the most appropriate advanced nuclear hydrogen production technology to be supported for further development and early deployment.

The US Department of Energy, Office of Nuclear Energy has been supporting development of HTE at the Idaho National Laboratory (INL) since 2003. INL has demonstrated HTE at small scale and up to the $15 \mathrm{~kW}$ scale with a hydrogen production rate in excess of $5000 \mathrm{NL} / \mathrm{hr}$ [8]. However, longterm performance degradation remains the biggest issue preventing commercialization of HTE technology. Nevertheless, continuous improvements on materials, seals, and microstructures have been achieved and various SOEC stacks have been tested to investigate plausible approaches to mitigate degradation at INL [9-12]. The major problems identified in previous stack tests were air electrode delamination, $\mathrm{Cr}$ vapor poisoning, microstructure degradation, and seal leakage.

Much of the research on SOECs studying performance and durability has been performed at the single cell level. Besides our efforts, only limited investigations have addressed the performance and durability issues of SOEC stacks. Ebbesen et. al. recently reported solid oxide cell (SOC) stack tests for steam electrolysis and $\mathrm{CO}_{2} /$ steam co-electrolysis [13]. Stack and glass seals designed by Topsøe Fuel Cells were used in their tests. Trace amounts of impurities in the inlet stream were claimed to have significant impact on the performance and durability of the stacks.

This paper provides a summary of results for SOEC stacks tested at INL. Stack tests included evaluation of initial performances and long term durability in the electrolysis mode. The objective of the test program is to identify degradation mechanisms and to find ways to improve SOEC stack durability.

\section{MATERIALS AND EXPERIMENTAL APPARATUS}

The state-of-the-art solid oxide stacks tested for this study were provided by Ceramatec Inc., Materials and Systems Research Inc. (MSRI), and Saint Gobain Advanced Materials (St. Gobain). Ceramatec used electrolyte-supported cells for the stacks, while MSRI and St. Gobain used electrodesupported cells. Three 10-cell stacks from Ceramatec, two 5cell stacks from MSRI, and one 3-cell stack from St. Gobain were tested at INL. The configurations of the stacks and testing fixtures are described below in detail.

The Ceramatec stack consists of 10 planar electrolytesupported SOECs, interconnects, flow channels, seal gaskets, and end plates. The exploded view of the stack is shown in Figure 1. The stack is externally manifolded with a cross-flow configuration. The air outlet face is open, allowing for placement of intermediate voltage taps and internal stack thermocouples, as needed. The standard materials used in Ceramatec SOECs are ScSZ electrolyte, Ni-Ceria

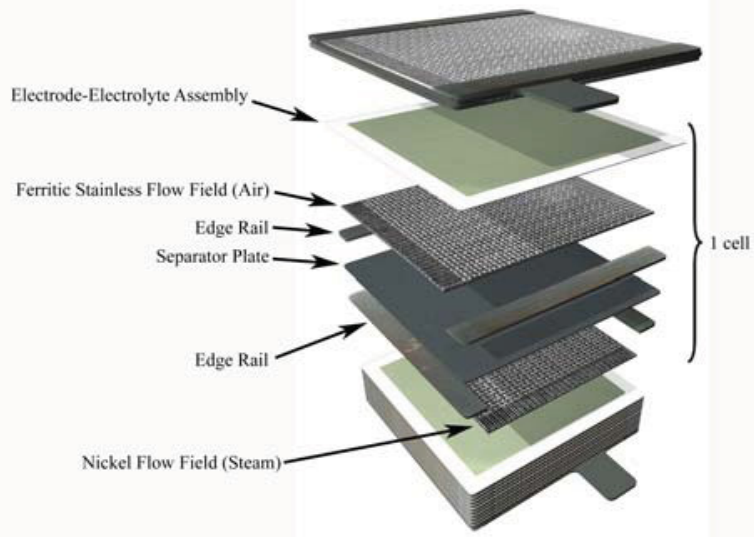

Figure 1. Exploded view of Ceramatec 10-cell stack.

steam/hydrogen electrode, and La-Co-Fe oxide based perovskite air electrode. Each SOEC has an active area of 45 $\mathrm{cm}^{2}$. Flow fields made of nickel and ferritic stainless steel (alloy 441) are used for gas distribution as well as current collection for the steam/hydrogen side and air side, respectively. The separator plate is also ferritic stainless steel. The ferritic stainless components are treated with a rare-earth coating/firing to support development of a stable electronically conducting protective oxide layer. Several different gasket materials were tested to minimize leakage issue.

An exploded view of a 5-cell MSRI stack is provided in Figure 2. The stack is internally manifolded with processing gases entering and exiting at the bottom of the stack, flowing in an inverted-U pattern in cross-flow. The oval flow passages around the periphery of the cells, interconnects and gaskets provide gas distribution to the micro-channel flow patterns in

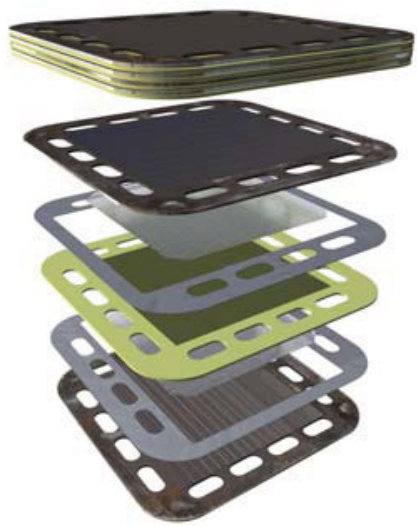

Figure 2. Exploded view of MSRI 5-cell stack.

the interconnects. The MSRI stack uses electrode-supported cells. Each MSRI stack has five identical Ni/YSZ-supported SOECs (Ni/YSZ-YSZ-LSCF) with an active area of $100 \mathrm{~cm}^{2}$. MSRI SOECs were fabricated using their state-of-the-art fabrication processes and the materials and microstructure of the cells were optimized specifically for operation in the electrolysis mode. Micro-channel flow patterns were directly 


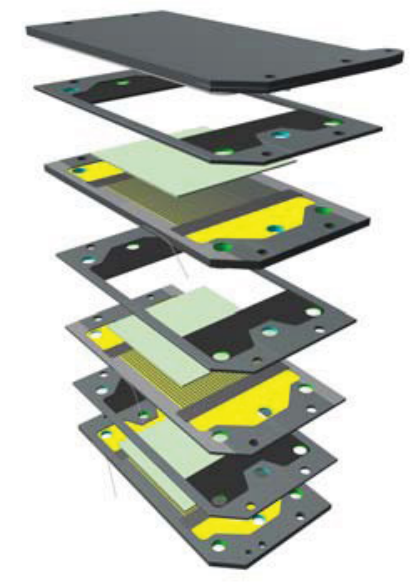

Figure 3. Exploded view of St. Gobain 3-cell stack.

machined into both surfaces of each interconnect, providing gas separation, current collection, and flow distribution. Contact aid was used to enhance electric conduction. Sealing was provided by a means of complaint seal developed by MSRI.
The St. Gobain cell and stack configuration was developed specifically for the long-term operation in the fuel cell mode. The design was developed at the Jülich Institute for Energy Research and licensed by St. Gobain. This stack geometry is designated the F design. The short stack includes three electrode-supported cells with metallic frames and interconnect plates fabricated from ferritic stainless steel (Crofer22APU). An exploded view of the stack is shown in Figure 3 . The stack is internally manifolded with a counter flow gas flow configuration. Each frame piece encloses a cell with a nickel mesh in contact with the steam-hydrogen electrode. The interconnects include grooves for air flow distribution. Each cell is $10 \times 10 \mathrm{~cm}$ in dimension with an active area of $81 \mathrm{~cm}^{2}$. The steam-hydrogen electrode material is Ni/YSZ cermet. The air electrode is LSM with a chromium evaporation protective layer and a contact (or bond) layer to minimize contact resistance with the interconnect. The air electrode includes both a functional layer of LSM and 8YSZ plus a cathode layer of pure LSM. The stack is sealed with a glass seal. The top and bottom metallic end plates include tabs for power connections.

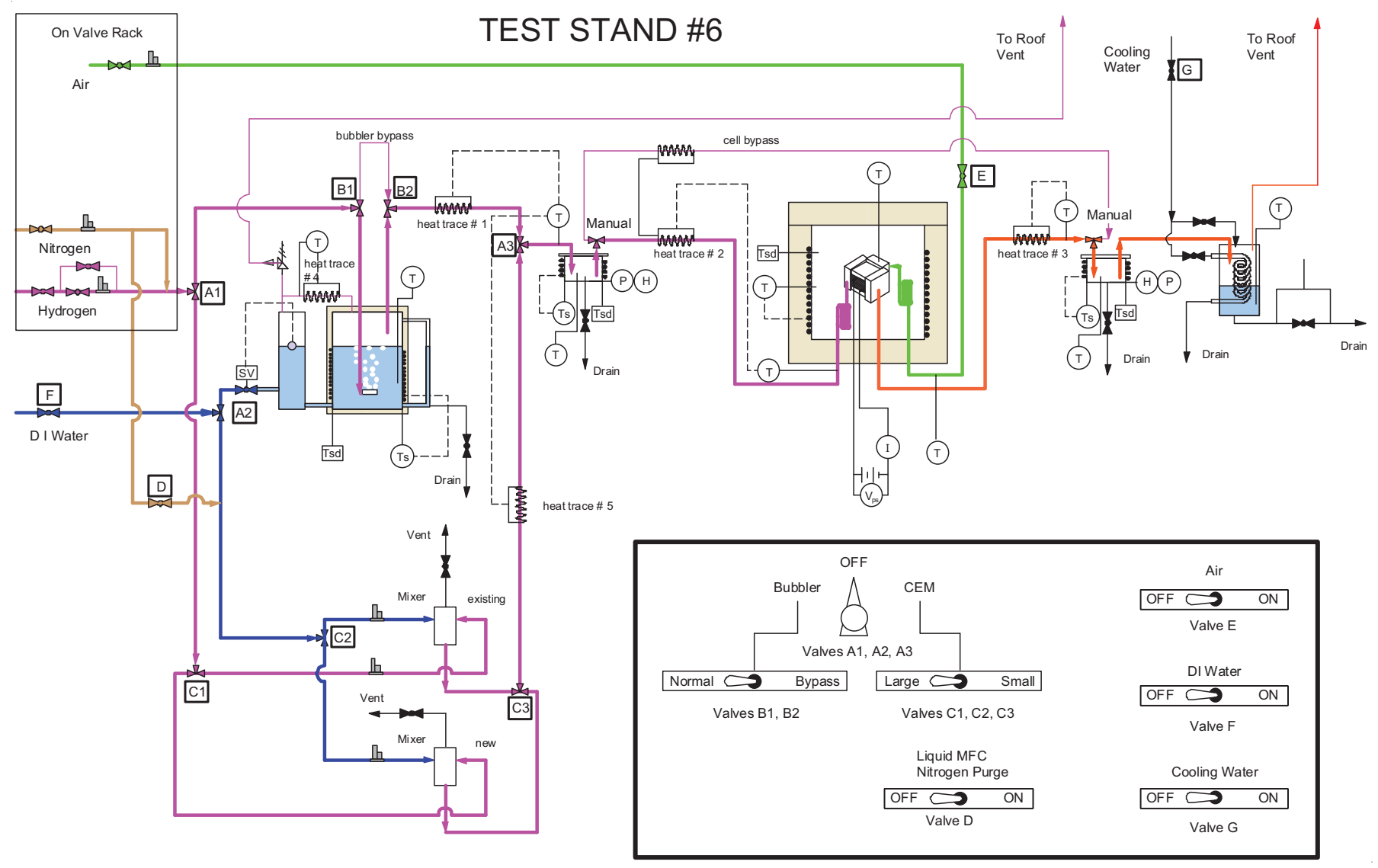

Figure 4: Piping and instrumentation diagram for the INL High Temperature Steam Electrolysis. 


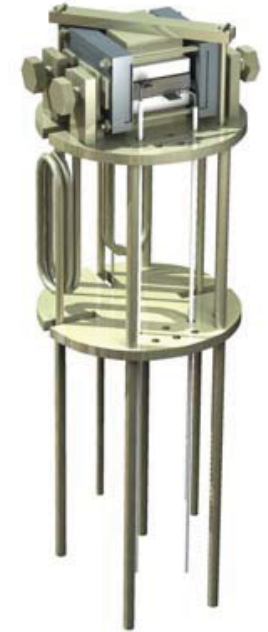

Figure 5. 3D view of the test fixture for Ceramatec stack testing.

A piping and instrument diagram (P\&ID) for stack testing is shown in Figure 4. Steam is generated either by bubbling carrier gas through the humidifier, or by a controlled evaporation and mixing (CEM) system (Bronkhorst USA Inc.). Bubbling gas through the humidifier is simple, but it is limited to a maximum steam content of about $55 \%$. One advantage of using the CEM system to deliver steam is that it can achieve higher steam content, as high as $90 \%$. The other advantage of using the CEM system is that steam content can be adjusted promptly compared to the humidifier, which usually takes more than one hour before stabilizing at a certain temperature. The carrier gases used in the CEM are either pure hydrogen or hydrogen and nitrogen mixture. Two CEM systems with different flow ranges, $100 \mathrm{~g} / \mathrm{hr}$ and $1000 \mathrm{~g} / \mathrm{hr}$, were used in the tests to evaporate liquid DI water. The carrier gas contains at least $10 \%$ hydrogen in order to prevent oxidation of the electrode. Humidity transducers are placed at the inlet and outlet of the stack in the steam hydrogen line to provide a direct measurement of steam consumption rate, which is equal to the hydrogen production rate on a molar basis. Measuring humidity therefore provides an independent verification of the hydrogen production rate for comparison to application of Faraday's law based on electric current.

The test fixture for testing Ceramatec stacks is shown in Figure 5. It shows a Ceramatec stack, mounted on its Inconel

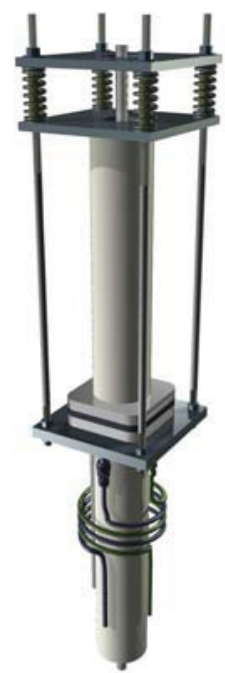

Figure $6.3 \mathrm{D}$ view of the test fixture for MSRI stack testing

test fixture, and rests on the furnace base. The power leads are Inconel rods insulated with alumina tubing. The hydrogen/steam and air inlet tubes are coiled to provide additional length for heat transfer upstream of the stack. The cross bar on top of the stack is used to apply compression load. The load can be adjusted by the springs underneath the test stand through the linkage rods. More detailed description of this experimental set-up can be found in [10].

A totally different test fixture was developed for testing MSRI stacks. Figure 6 provides a design rendering of the fixture. Two Inconel rods were welded vertically onto the top and bottom Inconel plates, working as the current collectors. The bottom alumina tube sitting on a stand (not shown) supports the whole test fixture. The top alumina tube is used to transfer the mechanical compression load from the springs to the stack and to insulate the top Inconel plate from the other parts. The spring loading assembly stays outside the furnace, so that the compression load can be adjusted during the heatup and curing processes. The stack was sandwiched between two Inconel plates, serving as the current collectors and the end plates for compression. Coiled tubes were welded onto the bottom Inconel plate for pre-heating of the inlet gases. Internal gas channels were also machined into the bottom Inconel plate for flow distribution.

Table I. The operating conditions in the stack testing.

\begin{tabular}{|c|c|c|c|c|c|c|c|c|}
\hline & \multirow[t]{2}{*}{ Stack } & \multirow{2}{*}{$\begin{array}{c}\text { Temperature } \\
{ }^{\circ} \mathrm{C}\end{array}$} & \multicolumn{3}{|c|}{ Flow Rate (slpm) } & \multirow{2}{*}{$\begin{array}{c}\text { Steam } \\
\text { Content }\end{array}$} & \multirow{2}{*}{$\begin{array}{c}\text { Current Density } \\
\left(\mathrm{A} / \mathrm{cm}^{2}\right)\end{array}$} & \multirow{2}{*}{$\begin{array}{c}\text { Steam } \\
\text { Generation }\end{array}$} \\
\hline & & & $\mathrm{H}_{2}$ & $\mathrm{~N}_{2}$ & Air & & & \\
\hline \multirow{3}{*}{ Ceramatec } & $\# 1$ & 800 & 1 & 1 & 5 & $56 \%$ & $0.25,0.317$ & Humidifier \\
\hline & $\# 2$ & 800 & 1 & 1 & 5 & $56 \%$ & 0.25 & Humidifier \\
\hline & $\# 3$ & 800 & 1 & 1 & 5 & $56 \%$ & 0.25 & Humidifier \\
\hline \multirow[t]{2}{*}{ MSRI } & $\# 1$ & 800 & 2.5 & 2.5 & $4.1 *$ & $70 \%$ & 0.2 & Large CEM \\
\hline & $\# 2$ & 800 & 0.75 & 0 & $4.1 *$ & $70 \%$ & 0.2 & Small CEM \\
\hline St. Gobain & $\# 1$ & 800 & 2.5 & 2.5 & 4 & $56 \%$ & 0.247 & Large CEM \\
\hline
\end{tabular}


The test fixture shown in Figure 6 was also used for St. Gobain stack testing. A base manifold flow adaptor unit was developed to accommodate the counter flow pattern of the St. Gobain stack. In addition, weights were used instead of springs per curing process requirement of St. Gobain stack.

Prior to each test, the furnace temperature was slowly ramped up to $800{ }^{\circ} \mathrm{C}$ or $850{ }^{\circ} \mathrm{C}$ with dry gases flowing through the stack. After reaching the operating temperature, each stack was conditioned in a reducing atmosphere for curing seals and reducing the steam/hydrogen electrode. By the end of the curing and reduction processes, both the inlet and the outlet humidity sensors will indicate $0{ }^{\circ} \mathrm{C}$ dew point. After the conditioning procedure, the furnace temperature was set at $800{ }^{\circ} \mathrm{C}$. Then the initial performance of each stack was evaluated by DC polarization scans in the electrolysis mode and the fuel cell mode. Both electrolysis and fuel cell sweeps were conducted at ambient pressure with different steam concentrations. The long term durability test in the electrolysis mode was performed immediately after the initial performance characterization. The operating conditions for each stack test are listed in Table I. In the Ceramatec stack tests, steam was generated by bubbling gas through a humidifier. Typically $56 \%$ inlet steam content was obtained by setting the humidifier temperature to $80{ }^{\circ} \mathrm{C}$. In the MSRI and St. Gobain stack tests, steam was produced by CEM system. $70 \%$ steam content was recommended for operating MSRI stacks as well as maintaining the reducing condition at the electrode.

\section{RESULTS AND DISCUSSION}

\section{Ceramatec Stacks}

A series of DC polarization sweeps were performed with different steam contents before the long term tests. The initial VI sweeps were conducted in both the fuel cell and the electrolysis modes, in order to evaluate the initial performance of the stacks. The bubbler temperature was set at $20^{\circ} \mathrm{C}, 50{ }^{\circ} \mathrm{C}$, $70{ }^{\circ} \mathrm{C}$, and $80{ }^{\circ} \mathrm{C}$ to humidify the fuel side inlet gas. The corresponding steam contents are $2.7 \%, 14.5 \%, 37 \%$, and $56 \%$. Figure 7 shows the results of the initial DC characterization of Ceramatec stack \#2. It is seen that the stack suffered from starvation at high current density in the electrolysis mode when the steam content is low. The nonlinearity in the curves at low steam content is associated with the high sensitivity of the Nernst potential to small changes in average steam content. Also, in the electrolysis mode, higher current densities can lead to steam starvation if the average steam content is low. A high inlet dew point temperature, typically $60^{\circ} \mathrm{C}$ or higher is suggested for longterm operation in the electrolysis mode [11]. Therefore, a voltage limit of the power supply was set for long term electrolysis operation, in order to prevent high voltage shock on the stack in the incident that the steam content is low.

Figure 8 presents results of a 1000-hour electrolysis longterm durability test of Ceramatec stack \#1. Constant current densities of $0.25 \mathrm{~A} / \mathrm{cm}^{2}$ and $0.317 \mathrm{~A} / \mathrm{cm}^{2}$, were applied

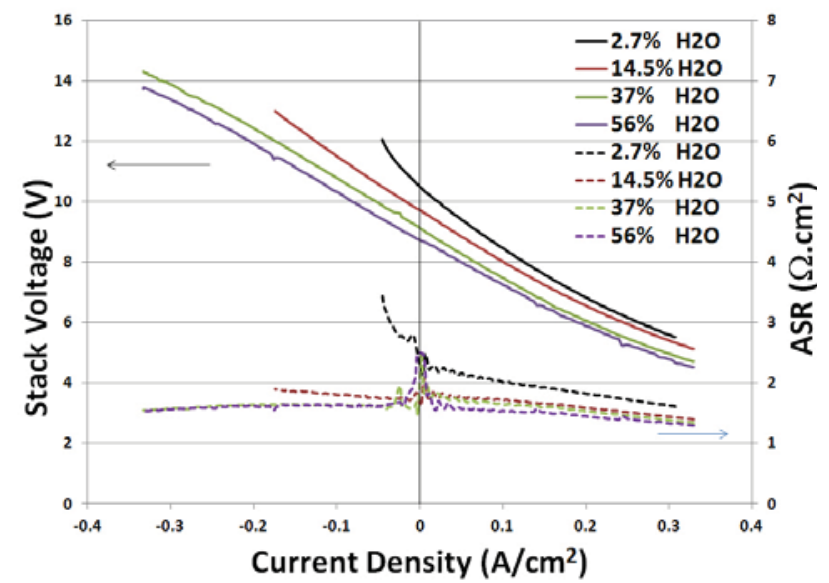

Figure 7. Initial VI sweeps with different steam contents of Ceramatec stack \#2. The calculated ASR values are shown as the straight lines. The stack is operated at $800{ }^{\circ} \mathrm{C}$ with ambient pressure.

alternately during the long term-test to evaluate the effect of current density on degradation. The average degradation rate at the lower current density is $5.66 \% / \mathrm{khr}$, while at the higher current density is $4.62 \% / \mathrm{khr}$. The degradation rate was calculated based on linear curve fitting of the stack voltage data. The average ASR is also lower at higher current density, which is consistent with the results obtained during initial polarization scans. The ASR increased from $1.25 \Omega . \mathrm{cm}^{2}$ to $1.52 \Omega . \mathrm{cm}^{2}$ when operating at $0.25 \mathrm{~A} / \mathrm{cm}^{2}$. These average results indicate a lower degradation rate at the higher current density. However, if degradation rates are recalculated from 300-1000 hours, the degradation rates at $0.25 \mathrm{~A} / \mathrm{cm}^{2}$ and $0.317 \mathrm{~A} / \mathrm{cm}^{2}$ are very close. In other words, increasing the current density has no obvious impact on the degradation rate at least for these conditions. Figure 8 also shows the intermediate stack voltages, which are the voltage drops across

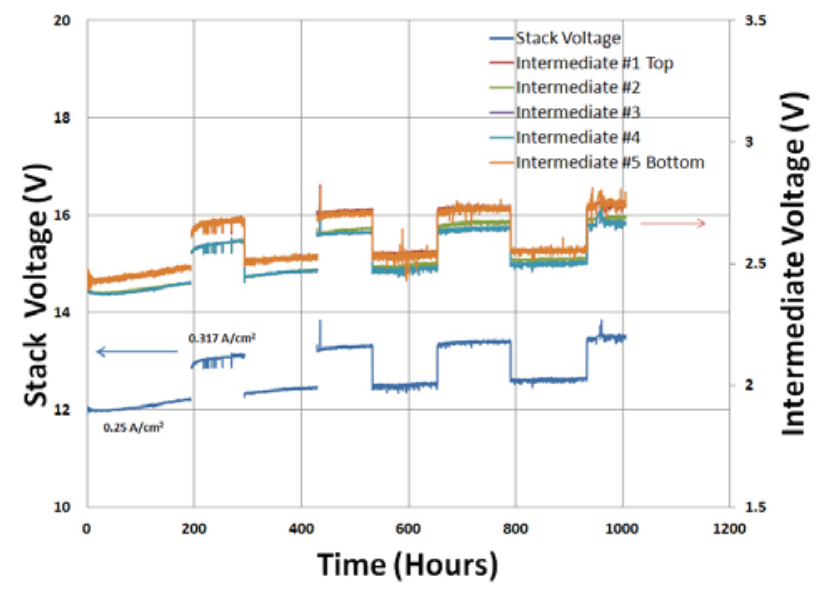

Figure 8. Ceramatec stack \#1 1000-hour electrolysis test with different current density applied alternately. 
two intermediate cells. It is seen that all the two-cell units behaved similarly during the tests.

Compared to previous stack tests $[10,12]$, Ceramatec stack \#1 demonstrated significant improvement on the durability of the SOEC stack. Several changes and improvements were included with this stack. First, the active area of each cell in stack \#1 was reduced from $61 \mathrm{~cm}^{2}$ to $45 \mathrm{~cm}^{2}$, which helps to manage the thermal stress distribution and improve sealing quality. Second, the material and microstructure on the air-side electrode were modified to mitigate the electrode delamination. Finally, the stainless steel based interconnects were pre-treated with spinel coatings to prevent oxidation and $\mathrm{Cr}$ vapor formation.

Figure 9 represents results of a 1000-hour electrolysis test of Ceramatec stack \#2. The stack was operated galvanostatically at $0.25 \mathrm{~A} / \mathrm{cm}^{2}$ during the long-term test. The average per-cell ASR increased from $1.69 \Omega . \mathrm{cm}^{2}$ to $1.77 \Omega . \mathrm{cm}^{2}$. Stack performance increased during the first 70 hours, which may be due to initial conditioning of the stack. Thereafter the stack performance started degrading. Based on the time period from 70 hours to the end of the test, the degradation rate is $6.87 \% / \mathrm{khr}$. The degradation rate is slightly higher than that of the stack \#1, mainly due to nonuniform behaviors of the cells in the stack. The intermediate voltages shown in Figure 8 indicate that some cells degraded faster than others. As a comparison, intermediate voltage \#5 degraded $11.3 \%$ over 1000 hours, while intermediate \#1 voltage degraded only $1.5 \%$ over 1000 hours.

Compared to the stack \#1, a modified composite functional layer that incorporates YSZ was added in each cell of the stack \#2 to improve bonding between the electrolyte and the air electrode. In addition, a novel coating was applied on each interconnect to further mitigate oxidation and $\mathrm{Cr}$ vapor formation. Either one of the improvement did not further mitigate the degradation, at least for some cells.

Figure 10 illustrates the performance of Ceramatec stack \#3 during long-term electrolysis. This stack was

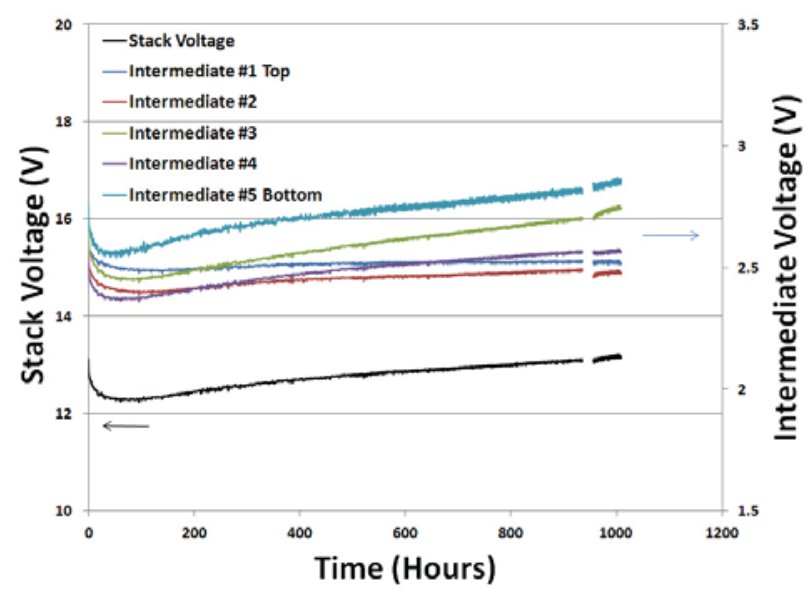

Figure 9. Ceramatec stack \#2 1000-hour electrolysis test at $0.25 \mathrm{~A} / \mathrm{cm}^{2}$.

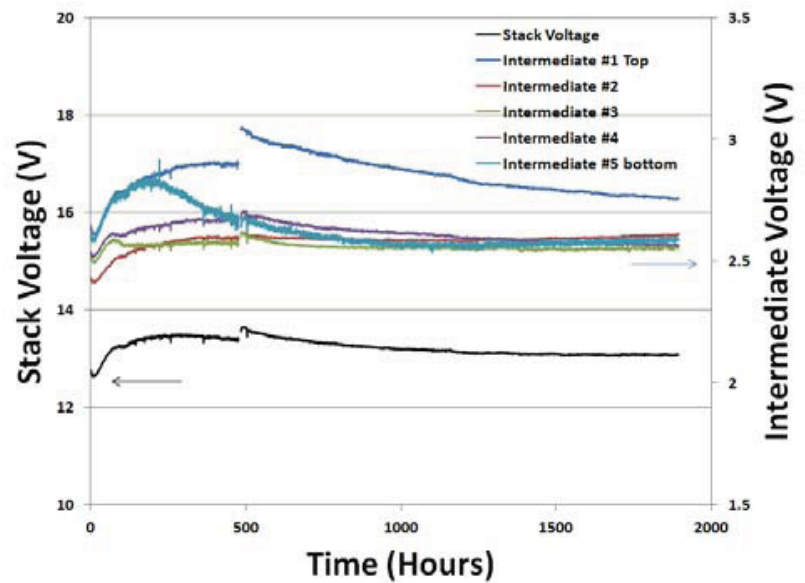

Figure 10. Ceramatec stack \#3 1900-hour electrolysis test at $0.25 \mathrm{~A} / \mathrm{cm}^{2}$.

operated galvanostatically at $0.25 \mathrm{~A} / \mathrm{cm}^{2}$ for about 1900 hours and it was by far the best performing Ceramatec stack that has been tested at INL. Unfortunately the stack test was shut down due to an off-normal event that happened at 1900 hours and the performance did not recover after that. The stack degraded over the first 200 hours, but thereafter the performance started increasing. After 1600 hours of operation, the stack voltage became stabilized. Based on the time period from 200 hours to the end of the test, the performance increased $7.4 \%$ over 1700 hours. Inlet and outlet dewpoint temperatures were constant over the period, indicating a constant hydrogen production rate consistent with the constant current conditions of the test. The initial and final average ASR values were $1.59 \Omega . \mathrm{cm}^{2}$ and $1.76 \Omega \mathrm{cm}^{2}$, respectively. The ASR reached the peak at $1.92 \Omega . \mathrm{cm}^{2}$ after a brief power outage that occurred around 500 hours. Intermediate voltages in the stack \#3 behaved differently over the first 500 hours. After that time, the intermediate voltages followed similar trends except for the top one, which seemed to be affected significantly by the power outage.

To our knowledge, this is the first time that a SOEC stack exhibited significant negative degradation (i.e. performance improvement) in a long-term durability test. However, the reason that caused this exceptional, yet promising behavior remains unclear and needs further investigation. A few factors different to the previous tests were found. In the preparation, the only difference between the stack \#3 and the previous one was the composition of the ceria-based functional layer used in each cell. During initial characterization in the fuel cell mode, this stack indicated oxygen starvation, despite adequate air flow. A problem with the sealing of the air inlet manifold was later discovered post-test. This problem did not impact operation in the electrolysis mode. However, none of these factors can easily explain the observed performance increase over the long time period. As a comparison, a Ceramatec button cell recently tested at INL also showed similar behavior [15]. Its performance also increased continuously over a 4000- 
hour operation in the electrolysis mode. Additional research is needed to fully understand this exceptional behavior.

\section{MSRI Stacks}

Initial characterization was also conducted on the MSRI stacks. DC potential sweeps were performed over a range of inlet steam content prior to the long term tests. During the initial performance evaluation, the lower steam content values were obtained by bubbling gas through the humidifier; while $70 \%$ steam content was achieved using the CEM system. Figure 11 shows the results of the initial DC characterization of MSRI stack \#2. Compared to Ceramatec electrolytesupported SOECs, MSRI electrode-supported cells have much lower ASR values, resulting in a higher energy efficiency during electrolysis.

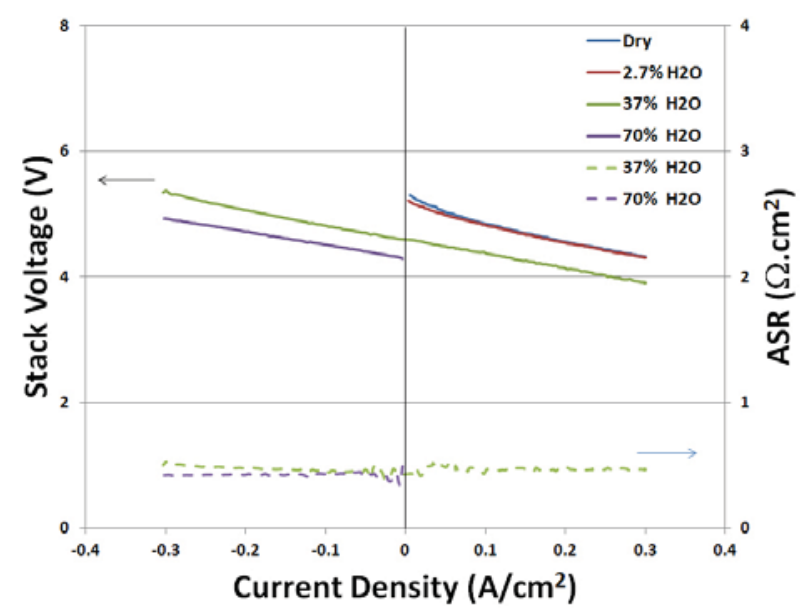

Figure 11. Initial VI sweeps with different steam contents of MSRI stack \#2. The calculated ASR values are shown as the straight lines.

Figure 12 represents the results of a long-term electrolysis test on MSRI stack \#1, which was operated galvanostatically at $0.2 \mathrm{~A} / \mathrm{cm}^{2}$ over 1000 hours. The overall degradation rate was $8.9 \% / \mathrm{khr}$, which is calculated based on linear curve fitting. The average ASR increased from $0.41 \Omega . \mathrm{cm}^{2}$ to $0.90 \Omega . \mathrm{cm}^{2}$. This degradation rate was higher than what had been achieved by MSRI, mainly due to the increased degradation of the top cell, as shown in Figure 12. The degradation rate of the top cell was $26.8 \% / \mathrm{khr}$, while other cells' were close to $3.7 \% / \mathrm{khr}$. The increased degradation of the top cell might be caused by the cooling effect of a large gas flow on the electrodes (due to the minimum gas flow requirement of large CEM). It could also be attributed to $\mathrm{Cr}$ poisoning since the top cell had direct contact with Inconel current collector on the air side. A special surface treatment was suggested to mitigate the top cell degradation.

Compared to the test of MSRI stack \#1, the operating conditions were adjusted for the stack \#2. The fuel-side carrier gas flow rate was decreased from $5 \mathrm{slpm}$ to $0.7 \mathrm{slpm}$ by

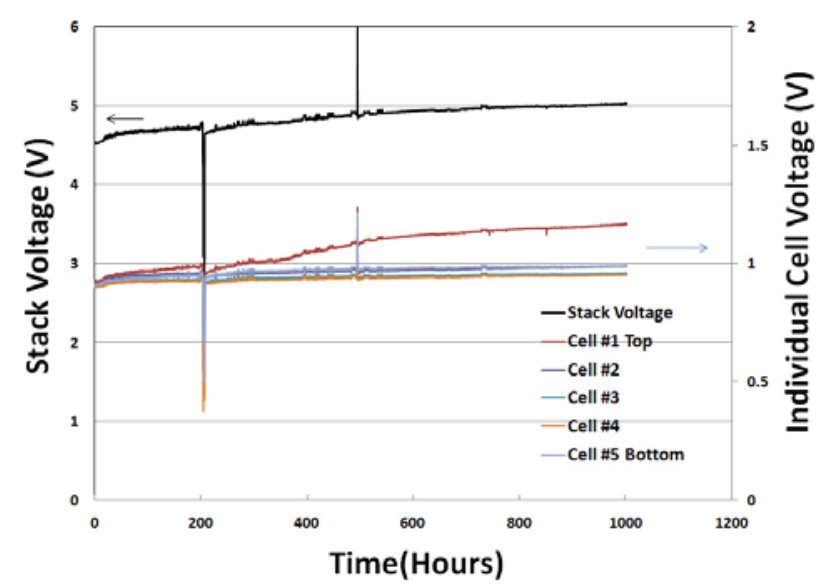

Figure 12. MSRI stack \#1 1000 hour electrolysis test at $0.2 \mathrm{~A} / \mathrm{cm}^{2}$.

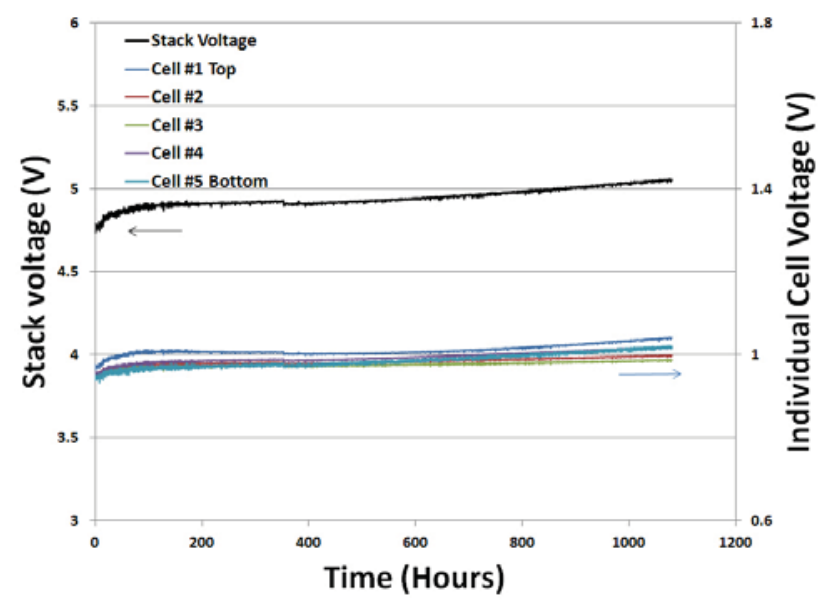

Figure 13. MSRI stack \#2 1100 hour electrolysis test at $0.2 \mathrm{~A} / \mathrm{cm}^{2}$ with steam utilization fixed at $40 \%$.

switching from the large CEM system to the small CEM system. Also, pure hydrogen was used instead of hydrogen/nitrogen mixture. The adjustment resulted in a higher steam utilization value of $40 \%$. Figure 13 shows the results of a long term electrolysis test on MSRI stack \#2. The stack was operated galvanostatically at $0.2 \mathrm{~A} / \mathrm{cm}^{2}$ for 1100 hours with an overall degradation rate of $3.2 \% / \mathrm{khr}$. The improvement of the overall stack durability was mainly attributed to the adjustment of the operating conditions and/or the modification of the top cell. Examination of Figure 13 reveals that all the cells behaved similarly during the longterm test, which indicates that the treatment on the top cell significantly mitigated its degradation. An alternative way to mitigate the top cell degradation is by adding a dummy cell to separate the top cell and the Inconel plate. In this case, the dummy cell works as a barrier as well as a current collector. 


\section{St. Gobain Stack}

Different than the previous SOEC stacks, the St. Gobain stack was actually developed as an SOFC stack. Stable performance was expected in the fuel cell mode, while its behavior in the electrolysis mode was unknown. During the initial performance evaluation, steam was generated by the CEM system. Prior to operation in the electrolysis mode, the stack was operated in the fuel cell mode for 250 hours until it stabilized. Figure 14 shows the results of polarization scans before and after the fuel cell operation. These VI curves that the stack performance in both modes of operation actually increased during the 250 hours of fuel cell operation.

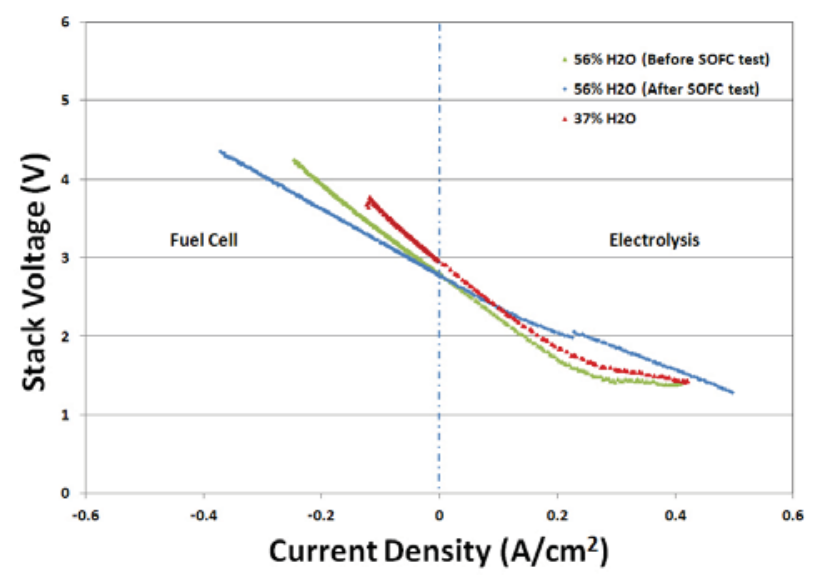

Figure 14. VI sweeps of the St. Gobain stack before and after being operated in the fuel cell mode for 250 hours.

After the 250 hours of fuel cell operation, the stack was switched into the electrolysis mode. The behavior of the stack in long term operation is presented in Figure 15. For the first 250 hour operation in the fuel cell mode, the stack performance gradually increased and then stabilized. No degradation was observed during the fuel cell operation. However, immediately after being switched to long-term electrolysis mode, the stack started rapid degradation, at a rapid rate of roughly $50 \%$ per 100 hours. In addition, all three cells behaved similarly during fuel cell operation, but the individual cell voltages diverged in the electrolysis mode. The stack was shut down after 100 hours of electrolysis testing due to the rapid degradation. Major cracks/delamination of the airelectrode was found on the top cell in the post-test observation. Reaction between Inconel plate and the stack top plate was also found.

The data of this stack test was consistent with the results of St. Gobain single cells [15]. All of the St. Gobain single cells exhibited stable performance in the fuel cell mode, but suffered from severe degradation in the electrolysis mode. These results suggested that St. Gobain SOFCs cannot be directly used for electrolysis. The optimization for long durability of SOFCs may not work in the electrolysis mode.

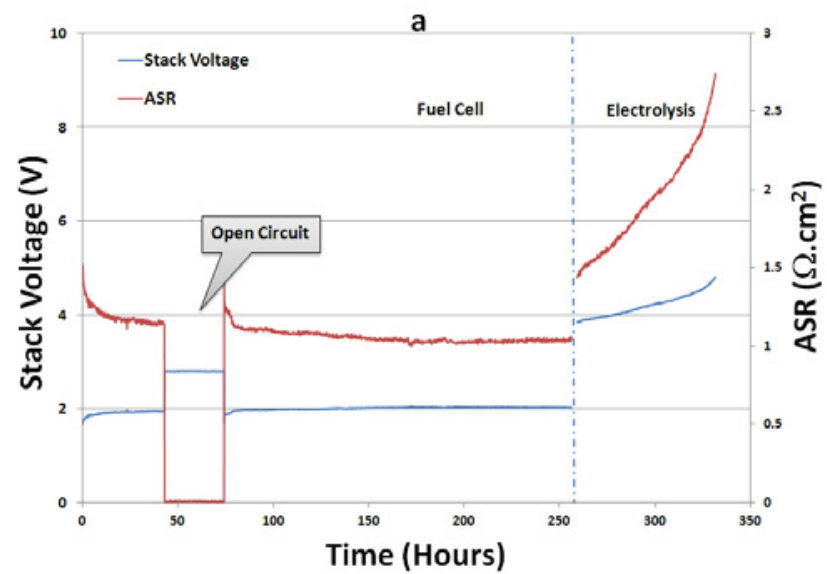

b

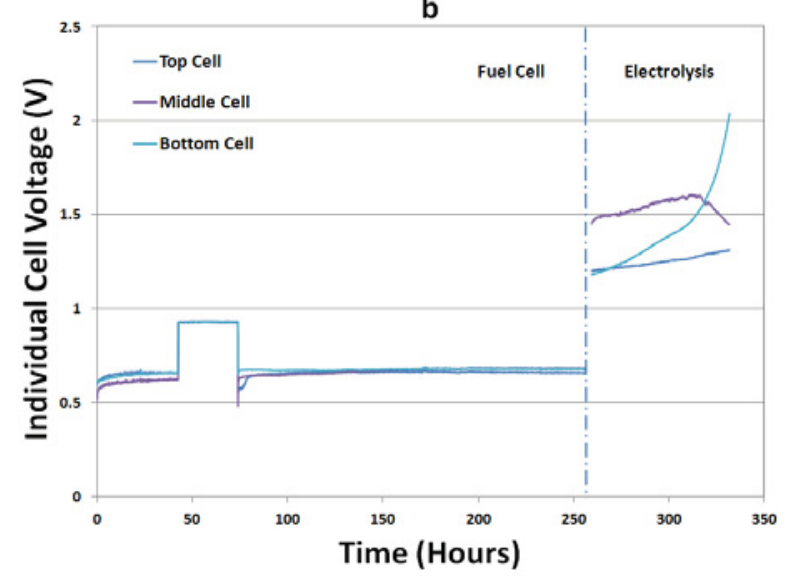

Figure 15. Long term test of the St. Gobain stack in the fuel cell mode and the electrolysis mode at $0.247 \mathrm{~A} / \mathrm{cm}^{2}$.

Modification on the microstructure was suggested to St. Gobain before any additional electrolysis tests.

\section{CONCLUSION}

Significant improvements on the SOEC stack durability have been achieved. The state-of-art stack design, incorporating advanced materials, and the novel treatment of interconnects help to mitigate the degradation of the SOEC stacks in electrolysis operations. Three electrolyte-supported SOEC stacks provided by Ceramatec were tested. The degradation rates of the first two stacks were between $4.62 \% / \mathrm{khr}$ and $6.87 \% / \mathrm{khr}$. The third stack demonstrated exceptional performance, which showed negative degradation over 1900 hour test. This is the first SOEC stack ever documented in the literature for which the performance increased steadily during a long-term electrolysis tests. However, the factors that caused this exceptional result remain for further investigations. Two electrode-supported SOEC stacks provided by MSRI showed promising long-term durability. The most recent stack demonstrated an overall degradation rate of $3.2 \% / \mathrm{khr}$, which was the best result 
obtained to date at INL. The electrode-supported St. Gobain SOFC stack showed stable performance in the fuel cell mode, but experienced rapid degradation in the electrolysis mode. It further proved that SOFC stacks cannot be directly used for HTE. Modifications are needed on St. Gobain cells in order to be operated in the electrolysis mode. A degradation rate of $\sim 1 \% / \mathrm{khr}$ or lower is needed for commercialization of SOEC stacks for high temperature electrolysis. More stacks are under testing at INL to verify various strategies for further mitigating the degradation.

\section{NOMENCLATURE}

Materials and Systems Research Inc.

MSRI

Saint Gobain Advanced Materials Inc. St. Gobain

High temperature electrolysis HTE

Solid oxide electrolysis cell SOEC

Solid oxide fuel cell $\quad$ SOFC

Idaho National Laboratory INL

Piping and instrument diagram P\&ID

Controlled evaporation and mixing CEM

Area specific resistance ASR

Open circuit voltage OCV

\section{ACKNOWLEDGMENTS}

This work was supported by the U.S. Department of Energy, Office of Nuclear Energy, Nuclear Hydrogen Initiative and Next Generation Nuclear Plant Programs under DOE Operations Office Contract DE-AC07-05ID14517.

\section{REFERENCES}

1. National Academies, National Research Council and National Academy of Engineering, The hydrogen economy: opportunities, costs, barriers, and R\&D needs, National Academies Press, Washington, 2004.

2. Basic Research Needs for the Hydrogen Economy, Report of the basic energy sciences workshop on hydrogen production, storage, and use, May13-15, 2003, available at http://www.sc.doe.gov/bes/reports/files/NHE_rpt.pdf

3. Hydrogen, Fuel Cells \& Infrastructure Technologies Program, 2.0 Program Benefits, 2007, U.S. Department of Energy, available at http://www1.eere.energy.gov/ hydrogenandfuelcells/mypp/

4. Turner, J.A., "Sustainable Hydrogen Production," Science, 305, pp. 972-974, 2004

5. Holladay, J.D., Hu, J., King, D.L., and Wang, Y., "An overview of hydrogen production technologies," Catalysis Today, 139(4), pp. 244-260, 2009.

6. O'Brien, J. E., "Review of the Potential of Nuclear Hydrogen for Addressing Energy Security and Climate Change," Nuclear Technology, Vol. 178, April 2012.

7. Varrin, R. D., Reifsneider, K., Scott, D. S., Irving, P., and Rolfson, G., "NGNP Hydrogen Technology DownSelection; Results of the Independent Review Team
Evaluation," Dominion Engineering report\# R-6917-0001, August, 2009.

8. Stoots, C. M., O’Brien, J. E., Condie, K., MooreMcAteer, L., Housley, G. K., Hartvigsen, J. J., and Herring, J. S., "The High-Temperature Electrolysis Integrated Laboratory Experiment," Nuclear Technology, April, 2009.

9. O'Brien, J. E., Stoots, C. M., Herring, J. S., Hartvigsen, J. J., "Performance of planar high-temperature electrolysis stacks for hydrogen production from nuclear energy," Nuclear Technology, 158(2), pp.118-131, 2007.

10. Herring, J. S., O'Brien, J. E., Stoots, C. M., Hawkes, G. L., Hartvigsen, J. J., Shahnam, M., "Progress in hightemperature electrolysis for hydrogen production using planar SOFC technology," International Journal of Hydrogen Energy, 32(4), pp.440-450, 2007.

11. Mawdsley, J. R., David Carter, J., Jeremy Kropf, A., Yildiz, B., and Maroni, V. A., "Post-test evaluation of oxygen electrodes from solid oxide electrolysis stacks," International Journal of Hydrogen Energy, 34(9), pp. 4198-4207, 2009

12. O'Brien, J. E., Stoots, C. M., Herring, J. S., Hartvigsen, J. J., "Hydrogen production performance of a 10-cell planar solid-oxide electrolysis stack," Journal of Fuel Cell Science and Technology, 3(2), pp. 213-219, 2006.

13. Stoots, C. M., O’Brien, J. E., Condie, K., Hartvigsen, J. J., "High-temperature electrolysis for large-scale hydrogen production from nuclear energy - Experimental investigations," International Journal of Hydrogen Energy, 35(10), pp. 4861-4870, 2010.

14. Ebbesen, S. D., Hogh, J., Nielsen, K. A., Nielsen, J. U., Mogensen, M., "Durable SOC stacks for production of hydrogen and synthesis gas by high temperature electrolysis," International Journal of Hydrogen Energy, 36(13), pp. 7363-7373, 2011.

15. Zhang, X., O’Brien, J. E., O’Brien, R. C., "Recent advances in high temperature electrolysis at Idaho National Laboratory: single cell tests," submitted to the ASME ESFuelCell2012. 